\title{
Dança diaspórica: (des)ocupações como elementos de interação
}

\author{
João Vítor Mulato \\ Sandra Meyer Nunes ${ }^{2}$
}

Recebido em: 31/08/2019

Aprovado em: 30/10/2019

DOI: $10.5965 / 2358092521222019117$

\footnotetext{
${ }^{1}$ Mestra pelo Programa de Pós-graduação em Artes Cênicas pela UFRN, graduada em Teatro pela mesma instituição e pedagoga pela UNINASSAU. Doutoranda no Programa de Pós-graduação em Teatro (PPGT) da UDESC. E-mail: joaovitormulatto@gmail.com

${ }^{2}$ Doutora em Artes, Comunicação e Semiótica pela PUC-SP. Mestra Foi professora Titular da Universidade do Estado de Santa Catarina de 1989 a 2016, tendo atuado no Curso de Licenciatura em Teatro e no Programa de Pós-graduação em Teatro. E-mail: meyersandra0@gmail.com
} 


\section{RESUMO}

Trata-se, esse material, de um relato de vivência que ocorreu no ano de 2018, na cidade de Belo Horizonte, Minas Gerais, no $50^{\circ}$ Festival de Inverno promovido pela UFMG, com a artista, pesquisadora e pedagoga em Dança, Dudude Herrmann (MG). O objetivo central da interlocutora é relatar o processo artístico vivenciado, da desocupação e ocupações de espaços urbanos como potência criativa em dança e a intersecção entre a mencionada linguagem com a Música. Faz-se mister apontar que ocupar territórios com arte é também um ato político, sobretudo, quando as composições artísticas ocorrem em coralidade. Para tanto, a artista-pesquisadora abarca enquanto teoria o conceito do sujeito da experiência (LARROSA, 2017) e dos ritos de passagem (GENNEP, 2011), para justificar as costuras nas práticas artísticas vivenciadas.

Palavras-chave: Criação e(m) Dança, Experiência Diaspórica, Ritos de Passagem.

\section{ABSTRACT}

This work addresses a report of an experience lived in 2018 in the 50th Winter Festival of the Federal University of Minas Gerais (UFMG) in Belo Horizonte, a city in the state of Minas Gerais, Brazil. The festival was promoted by the UFMG and counted with the artist, researcher and pedagogue in Dance, Dudude Herrmann. The main goal of the interlocutor is to relate the artistic process experienced by herself about the use and disuse of urban spaces as creative power of dance and the intersection between Dance and Music. Therefore, pointing at the fact that the occupation of territories by art is also a political act is an essential action, especially when the artistic compositions occurs in chorality. For this purpose, the artist-researcher embraces as theory the concept of the subject of experience (LARROSA, 2017) and the rites of passage 
(GENNEP, 2011), in order to justify the threads of the experienced artistic practices.

Keywords: Creation and/in dance, Diasporic experience, Rites of passage.

\section{INTRODUÇÃO: A GÊNESE DA EXPERIÊNCIA EM DANÇA}

Esse material é fruto de uma vivência/residência artística que ocorreu na cidade de Belo Horizonte, Minas Gerais, no ano de 2018, e a corrente interlocução gira em torno da desocupação das salas fechadas; Teatros da UFMG e as ocupações dos espaços urbanos de $\mathrm{BH}$ como contexto político-social de interação, aonde as pesquisadoras avistaram no horizonte a criação em Dança a partir da relação com os espaços abertos. Dessa forma, o deslocamento de um corpo pode ser interpretado como possíveis aberturas de caminhos, sendas de criações, resultando assim em novas experiências, ou como costumo pensar, ritos de passagem. Integro Experiência nesse texto partindo da perspectiva de Jorge Larrosa (2017), e Ritos de Passagem a partir de Arnold van Gennep (2011), uma vez que ambos os autores dialogam sobre viver e transformar-se constantemente a partir das afetações em contexto social. Aqui, as experiências e os ritos de passagem são qualificados como possíveis colorações na criação da linguagem das artes e, as afetações foram resultados de uma vivência diaspórica ${ }^{3}$ em Dança, a qual atingiu um grande número de indivíduos; de artistas-pesquisadoras a espectadoras em estado de troca.

Penso incessantemente que da mesma forma que as ruas nos transformam devido ao seu locus da experiência, nós tam-

3 A palavra Diáspora/Diaspórica aqui inserida é devido ao deslocamento que ocorreu na gênese da vivência artística, sendo um incentivo, algo convidativo, da parte das mediadoras do evento artístico. 
bém as transformamos, havendo uma troca constante entre os sujeitos e os espaços. Se pararmos para pensar, tudo aquilo que fazemos nas ruas não permanece registrado apenas em nós, mas também nos próprios territórios. Ou seja, há uma reciprocidade criativa e propositiva que nos abre as possibilidades. Em resumo, os nossos fluxos permanecem latentes nas zonas, tal como tudo aquilo que nos atravessou. Por esse motivo é que inauguro essa comunicação textual chamando-a de relato de experiência, pois trata-se daquilo que em mim ficou que e, segundo Larrosa,

\begin{abstract}
A experiência, e não a verdade, é que o dá sentido à escritura. Digamos, com Foucault, que escrevemos para transformar o que sabemos e não para transmitir o já sabido. Se alguma coisa nos anima a escrever é a possibilidade de que esse ato de escritura, essa experiência em palavras nos permita liberar-nos de certas verdades, de modo a deixarmos de ser o que somos para ser outra coisa, diferente do que viemos sendo. Também a experiência, e não a verdade, é o que dá sentido à educação. Educamos para transformar o que sabemos, não para transmitir o já sabido. Se alguma coisa nos anima a educar é a possibilidade de que esse ato de educação, essa experiência em gestos, nos permita liberar-nos de certas verdades, de modo a deixarmos de ser o que somos, para ser outra coisa para além do que vimos sendo. (LARROSA, 2017, p. 05)
\end{abstract}

Para mim, tornou-se pertinente citar o autor Jorge Larrosa após ter percebido, há um tempo, que me encontro em uma transição/transformação do eu, considerando-me um ser volátil nas pesquisas voltada à linguagem da dança e, de modo geral, das artes. Contudo, afirmo que jamais poderei falar de algo que não tenha me perpassado de alguma maneira. Aquilo que se encontra em mim é, relativamente, resultante de aspectos pertencentes a minha trajetória e experiências, à vista disso, é apenas me abrindo a elas e tendo noção de sua dimensão em minha vida que tenho a capacidade de dialogar comigo e me apresentar às outras pessoas. Sobre o processo da experiência, Larrosa afirma: 


\begin{abstract}
A experiência é algo que (nos) acontece e que às vezes treme, ou vibra, algo que nos faz pensar, algo que nos faz sofrer ou gozar, algo que luta pela expressão, e que às vezes treme, algumas vezes, quando cai em mãos de alguém capaz de dar forma a esse tremor, então, somente então, se converte em cantos. E esse canto atravessa o tempo e o espaço. E ressoa em outras experiências e em outros tremores e em outros cantos. Em algumas ocasiões, esses cantos de experiência são cantos de protesto, de rebeldia, cantos de guerra ou de luta contra as formas dominantes de linguagem, de pensamento e subjetividade. (LARROSA, 2017, p. 10)
\end{abstract}

Meus passos enquanto andarilha inexperiente na linguagem da Dança encontravam-se configurados apenas em espaços vistos enquanto "apropriados" para acontecerem, como salas de ensaios e teatros, e, se pararmos para refletir, esses espaços são ambientes fechados no qual limitam, de certo modo, a criação espontânea da pesquisadora; em alguns casos. De modo algum desejo apontar que os espaços fechados são ruins, quando na verdade, são maneiras outras de realizar investigações. Todavia, quando nos abrimos às cidades é que percebemos o quão elas são espaços de subjetivação, criação, interatividade, liberdade e arte. Confesso que passei a enxergar essas novas formas de afetar e ser afetada a partir da vivência com a pedagoga em dança, Dudude Herrmann (MG), quando ela propôs a um coletivo de artistas uma criação nos espaços alternativos às salas fechadas, durante $050^{\circ}$ Festival de Inverno promovido pela Universidade Federal de Minas Gerais (UFMG).

Meu corpo encontrava-se moldado aos espaços fechados, e não foi difícil eu reconhecer isso, pois, quando saímos do Teatro comecei a estranhar o ambiente externo. Confesso que de minha parte havia uma maior familiarização instaurada ainda na infância, aonde me sentia mais confortável ocupando as salas fechadas. Atualmente, leio esses espaços como jaulas, como aquelas que impedem os animais de serem livres. Teço esse comparativo por perceber que ao me abrir ao novo, aos espaços urbanos, senti uma liberdade maior, mas não no primeiro momento da imersão. 
Antes mesmo de incitar os corpos à criação, na intersecção entre dança e música, correlatos aos conhecimentos do músico Benjamin Taubkin e as suas pesquisadoras, a mediadora Dudude indagou que as criações em dança iriam ocorrer nos espaços alternativos, que no nosso caso, seria nas praças de Belo Horizonte, ao ar livre. O seu dito causou um estranhamento em todo coletivo de artistas, tanto nas bailarinas como nas musicistas. No entanto, ninguém se negou a fazer o deslocamento. Vale salientar que éramos um grupo de quase 40 pessoas, entre bailarinas, musicistas, fotografas e organizadoras, e talvez tenha sido essa uma das motivações que levaram as mediadoras, Dudude e Benjamin, a propor que o coletivo de artistas fosse para as ruas da cidade, realizar pesquisas em coralidade.

Lidar com diferentes energias, inúmeras ao mesmo tempo, seria imensamente complicado dentro do Teatro da Escola de Música da UFMG, visto que havia pessoas no espaço que nunca tinham se encontrado antes, dessa forma, entre o coletivo pairava o desejo de conhecer umas as outras. Recordo-me que os ecos tomavam conta do espaço com enorme facilidade; tanto das vozes, como dos instrumentos das musicistas. A experiência enquanto ocupação daquele novo lugar; de uma praça pública de Belo Horizonte, fora surpreendente, pois tínhamos que fazer emergir novas formas de pensar e desencadear a dança, sendo aquela troca um momento único.

Portanto, tivemos que não somente dançar em um espaço aberto e desconhecido, como também nos adaptar aos espaços, e não ele a nós, como geralmente acontecem em determinados ambientes. Nossa adaptação às praças ocorreu já no primeiro momento da vivência, durante a transição espacial, e eis um registro de nossa primeira reunião artística entre bailarinas. 


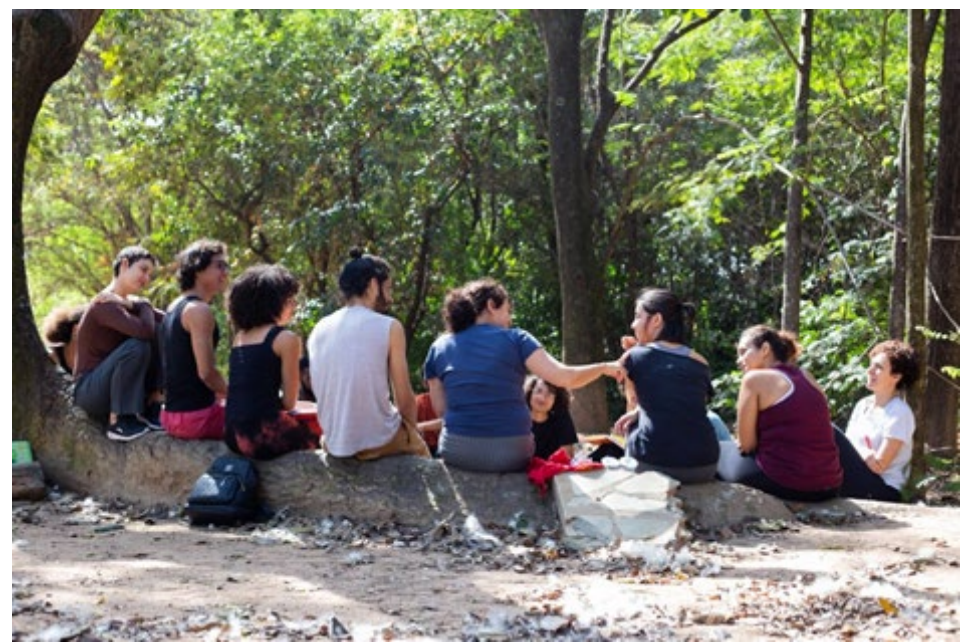

Figura 1: Parque Urbano de Belo Horizonte, Minas Gerais

Fonte: Arquivo pessoal da artista-pesquisadora

\section{DESENVOLVIMENTO: EM CAMPO, ACAMPA- MOS, CRIAMOS, DANÇAMOS}

Fomos para as ruas, mais precisamente para um parque, com nosso imaginário pulsando acerca de como faríamos para ressignificar os espaços. Debaixo de uma enorme árvore; como na imagem acima, Dudude iniciou as trocas com indagações acerca das intersecções não apenas entre Dança e Música - objetivo primordial da vivência -, mas também com tudo aquilo que encontrava-se a nossa volta, como a Natureza, os Animais e, principalmente, as Pessoas. Coloco em letra maiúscula os três nomes - natureza, animais e pessoas -, por terem sido importantes em toda nossa vivência, no mais, gostaria de apontar que em momento algum elas foram objetos de pesquisa, mas parte de nossa composição criativa. Recordo-me que a mediadora começou a nos falar da importância de tudo aquilo à nossa volta, o quão estávamos sendo privilegiadas por pesquisar 
poéticas em dança nos ambientes abertos. E, de fato, eu nunca havia tido a oportunidade.

Larrosa afirma que o sujeito da experiência necessita estar aberto às novas afetações, ou seja, aquilo que desconhecemos, para enfim, iniciar novos fluxos no contexto que é viver, e com isso avançar. Acerca disso, aponta:

A experiência, a possibilidade de que algo nos aconteça ou nos toque, requer um gesto de interrupção, um gesto que é quase impossível nos tempos que correm: requer parar para pensar, parar para olhar, parar para escutar, pensar mais devagar, demorar-se nos detalhes, surpreender o automatismo da ação, cultivar a atenção e a delicadeza, abrir os olhos e os ouvidos, falar sobre o que nos acontece, aprender a lentidão, escutar os outros, cultivar a arte do encontro, calar muito, ter paciência e dar-se tempo e espaço. (LARROSA, 2017, p. 25)

Após o diálogo inaugural sobre a mudança espacial, a mediadora nos direcionou a um processo de trocas, sobretudo com as pessoas que estavam conosco no ambiente, para que assim viéssemos a conhecer os corpos das desconhecidas e assim tentar conquistar a confiança a partir de um jogo de sensações com relação aos sentidos da percepção. A intenção da primeira vivência era descobrir, parcialmente, o espaço que estávamos ocupando ao desbravá-lo, sobretudo quando se tratava do corpo alheio a partir dos toques. Iniciamos o primeiro contato com uma dança convidativa entre bailarinas, musicistas e público, e tínhamos como objetivo mapear os corpos, fazendo aguçar sensações. 


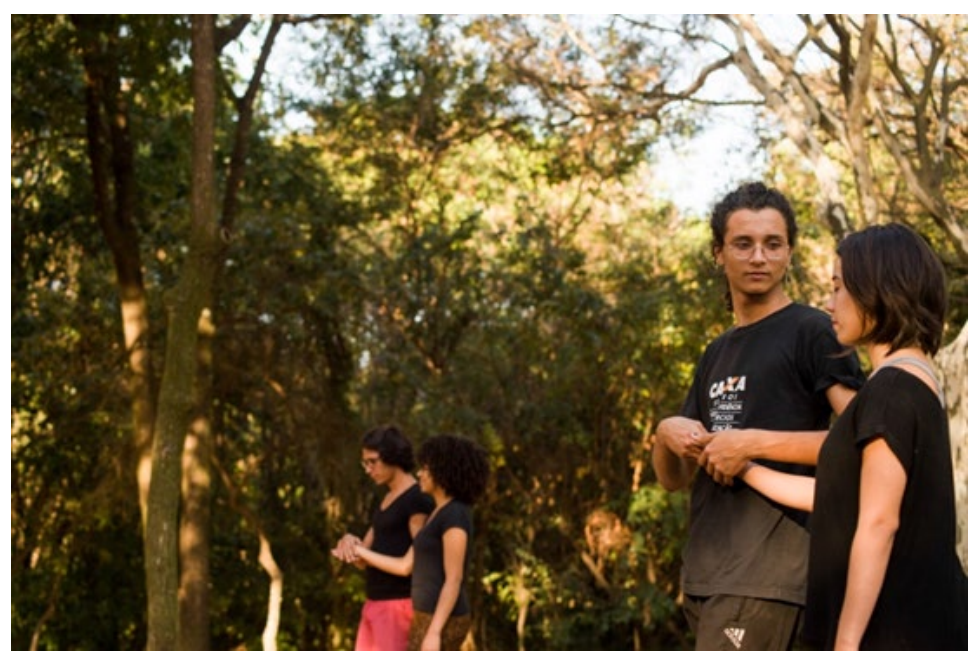

Figura 2: Parque Urbano de Belo Horizonte, Minas Gerais

Fonte: Arquivo pessoal da artista-pesquisadora

Não posso deixar de dizer que ao ocupar os espaços urbanos houve um maior desprendimento de técnicas - ao menos de minha parte -, quando na verdade estávamos sendo afetadas pela poética do espaço. A dança, muitas vezes, trata-se disso, de propiciar um olhar a nós e às outras. De enxergar possibilidades de criação em solos aonde necessita de semeadura, com isso, enlaço a citação acima de Larrosa às do antropólogo francês Arnold van Gennep, no qual ele nos fala mais diretamente sobre os Ritos de Passagem, enquanto processo único e transformador de nossa realidade. Gennep afirma que os ritos de passagem são ritos de abertura e transformações dos sujeitos em transição. Aponta também que ao ser agregada/inserida em novos territórios, ritos de passagem hão de surgir e tomar conta do sujeito como um todo. Em resumo, os ritos de passagem são algo cíclico, que se transforma constantemente, tal como o fato de viver. Segundo o autor, é 
[...] o próprio fato de viver que exige às passagens sucessivas de uma sociedade especial a outra e de uma situação social a outra, de tal modo que a vida individual consiste em uma sucessão de etapas, tendo por término e começo conjuntos da mesma natureza, a saber, nascimento, puberdade social, casamento [...]. (NUNES, 2019, p. 95 apud GENNEP, 2011, p. 26)

Ao fim da primeira experiência com a dança convidativa, a mediadora nos deu um novo comando, pedindo que ocupássemos um lugar no grande parque, cujo propósito era ligar-se, em primeira mão, a nós e a natureza, para depois sermos afetadas pelas músicas conduzidas por Benjamin e às musicistas.

Embora eu soubesse que viver é continuamente desagregar-se e reconstituir-se, mudar de estado e de forma, morrer e renascer, é agir e depois parar, esperar e repousar, para recomeçar em seguida a agir, porém de modo diferente (NUNES, 2019 apud GENNEP, 2011), revelo que durante os primeiros comandos da mediadora Dudude Herrmann acerca das danças em solo, meu corpo estava tímido pelo fato de que era algo novo para mim ocupar um parque tão amplo com uma dança pessoal e distante do virtuosismo que carrega a dança tradicional.

$\mathrm{Na}$ intenção de ampliar minhas camadas internas a partir de uma poética oriunda da natureza, fechei meus olhos e realizei uma pesquisa sensorial, ou seja, dancei a partir do toque do vento em meu corpo, bem como dos sons produzidos pelas árvores ao serem balançadas. Dancei como se eu fosse uma das enormes árvores. Uma dança que não exigiu esforços dos músculos, nem tão pouco me deixou com fadiga, coisa essa que as danças feitas nos ambientes fechados me era exigido constantemente.

Em qualquer caso, seja como território de passagem, seja como lugar de chegada ou como espaço do acontecer, o sujeito da experiência se define não por sua atividade, mas por sua passividade, por sua receptividade, por sua disponibilidade, por sua abertura. Trata-se, porém, de uma passividade anterior à oposição entre ativo e passivo, de uma passividade feita de paixão, de padecimento, de paciência, de atenção, como uma representatividade primeira, como uma disponibilidade fundamental, como uma abertura essencial. (LARROSA, 2017, p. 25 - 26) 


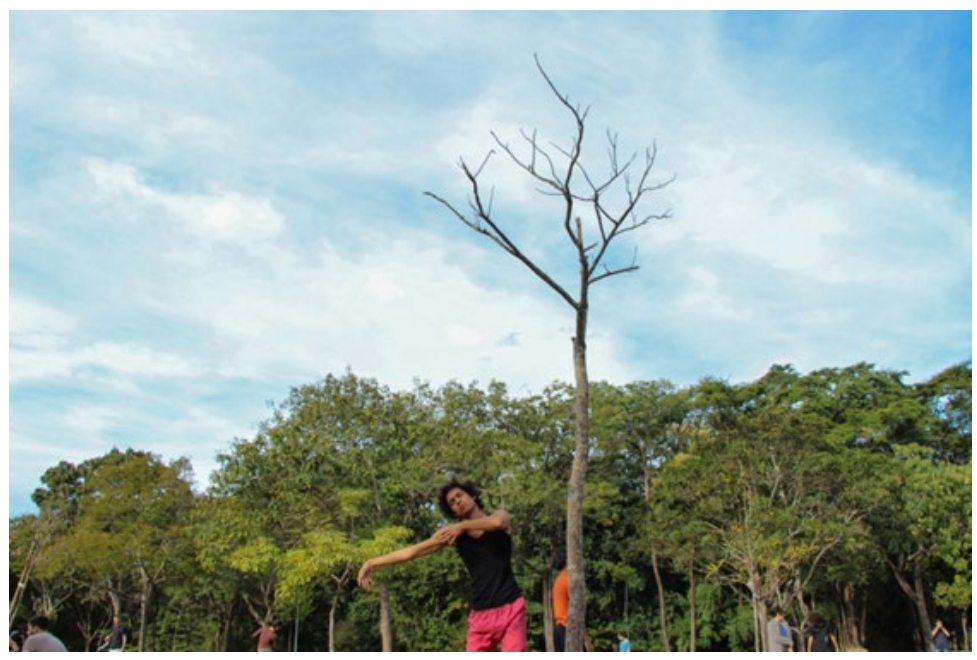

Figura 3: Parque Urbano de Belo Horizonte, Minas Gerais Fonte: Arquivo pessoal da artista-pesquisadora

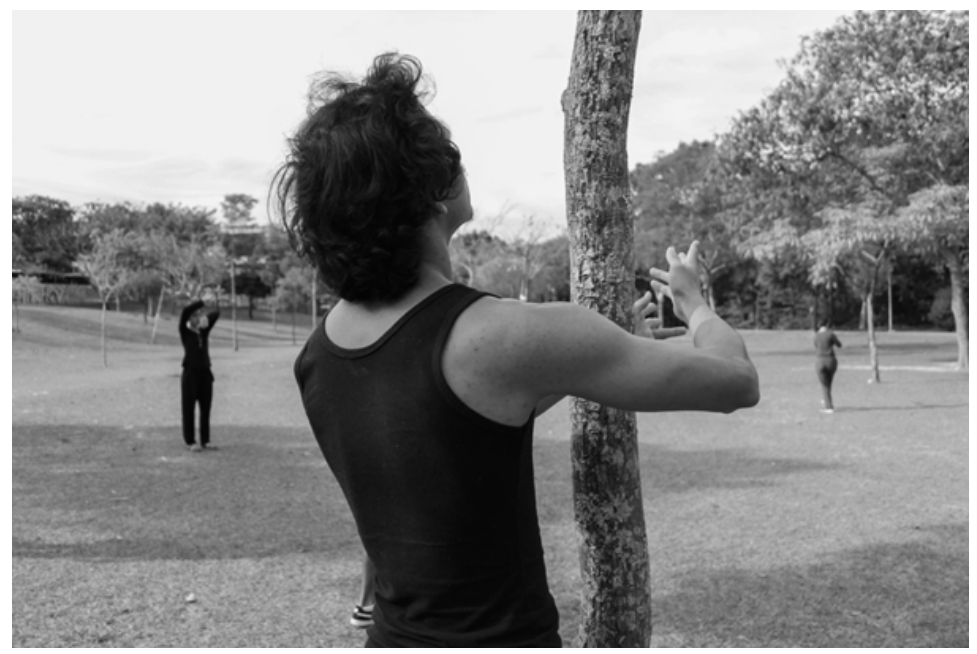

Figura 4: Parque Urbano de Belo Horizonte, Minas Gerais Fonte: Arquivo pessoal da artista-pesquisadora 
Em conexão comigo mesma, logo a fluidez de meu corpo entrou em atividade a partir da relação com a natureza e em meu diário de bordo me questionei sobre a criação e reverberação, dizendo: em um lugar tão aberto, como ficar tão atenta a própria criação e singularidade, visto que estou sendo atravessada por várias coisas ao mesmo tempo? Como (re)conhecer e identificar a própria música em um espaço tão amplo como um parque? As respostas encontravam-se nas vivências, as quais ampliavam minhas percepções a partir dos estímulos em dança. Em si, no movimento físico, aonde, ao me questionar e tentar traduzir essas percepções, estimulava as outras à minha volta, pensando e agindo assim, em conjunto, sobre os possíveis caminhos a serem tomados espontaneamente, me vi dançar com liberdade. Com isso, "a experiência seria o modo de habitar o mundo de um ser que existe, de um ser que não tem outro ser, outra essência, além da própria existência corporal, finita, encarnada, no tempo e no espaço, com os outros" (LARROSA, 2017, p. 43).

Nos três primeiros dias da vivência nos adaptamos e criamos partituras a partir da relação com tudo aquilo que se encontrava nos espaços urbanos e ao sermos guiadas, já no quarto dia, para as salas de ensaio, nossa dança fora mais contida devido à espacialidade, impedindo assim as ampliações enquanto movimento. De fato, estar nas ruas nos proporcionou uma dança mais livre, e isso foi presente nas trocas de informações com a Dudude, quando ela nos perguntou sobre a experiência em sala. De um modo geral, acredito que a limitação aos corpos foi devido ao grande número de pessoas em um pequeno espaço. Em resumo, a dança feita em sala era mais interna e reverberava com pequenos toques entre umas e outras, como na imagem abaixo, sendo eu e a Dudude. 


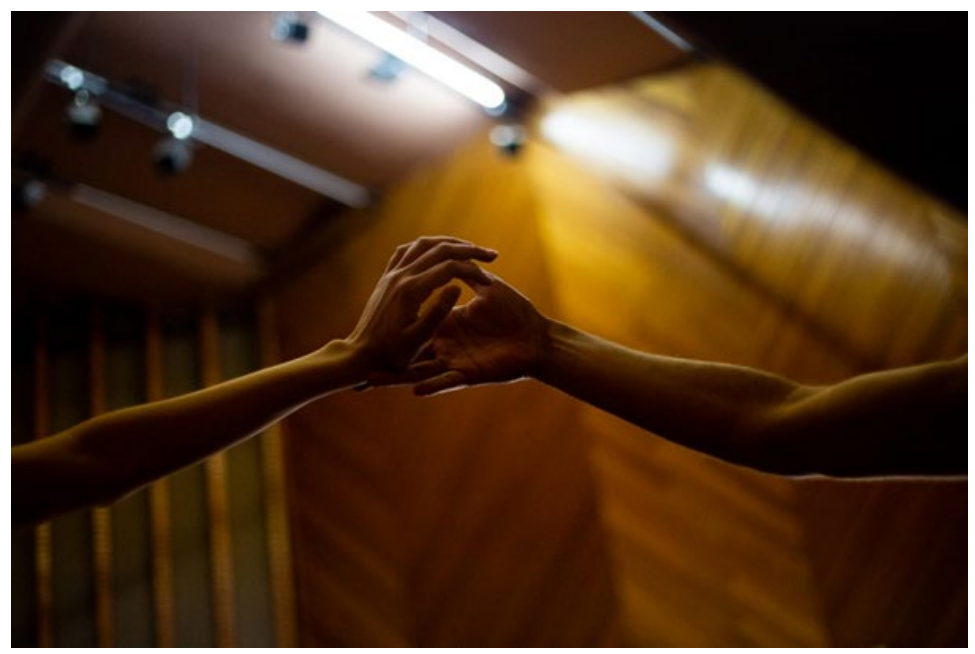

Figura 5: Teatro da UFMG, Belo Horizonte, Minas Gerais

Fonte: Arquivo pessoal da artista-pesquisadora

Tratando do contexto da troca, ficou posto no grande grupo que era mais válido estabelecer contato com as pessoas que se colocavam enquanto público, do que com as próprias bailarinas, visto que todas as dançantes já conheciam, parcialmente, os corpos umas das outras e assim dominar com certa propriedade os movimentos, o ato. Quando dançávamos com o público, em uma dança convidativa, éramos também convidadas a nos adaptar não somente aos espaços, mas, principalmente, ao corpo alheio, respeitando assim, os limites, as chegadas e as saídas, bem como suas recusas.

Havia uma maior surpresa nas ruas, sobretudo nas pessoas, nos diferentes corpos. Algo mais autêntico e atravessador. Vale levar em consideração que as espectadoras ao serem convidadas a dançar ou, ao parar para nos observar dançando, elas abandonavam, parcialmente, o que estavam fazendo e nos acompanhava, retroalimentando uma troca imensamente generosa. Emergindo assim danças mais pessoais. Todos esses apontamentos foram colocados pelo coletivo no quarto dia de imersão, quando voltamos para o Teatro da UFMG. 
Afirmo que para mim não foi ruim ser colocada novamente dentro de quatro paredes, visto que pude analisar como a arte se transformou e ramificou naquele espaço. No entanto, ao estar adaptada aos espaços urbanos após três dias de vivência, avistando danças livres, observando o público interagir com as artistas e seus corpos, fora no mínimo diferente. Eu sentia que dentro do Teatro eu dançava para mim e nenhum movimento era novidade para as demais pessoas. Nas ruas, eu estava dançando para as outras, pois sabia que existia um público que observava atentamente, à espera da interação. Havia um compartilhamento, uma troca generosa. É pertinente, do ponto de vista dessa interação e formação de público levar a arte para os espaços abertos, para que as pessoas ao redor visualizem os fazeres artísticos que se iniciam nas universidades, academias e escolas de dança.

\section{CONCLUSÃO: A TRANSFORMAÇÃO E RES- SIGNIFICAÇÃO DO EU-ARTE}

A meu ver, a comunidade necessita saber e ver o que as artistas andam praticando dentro de quatro paredes, para que assim elas se sintam interessadas a se deslocarem aos teatros convencionais. Compartilho do ideário de que não devemos fazer arte para quem já é do meio artístico, visto que essas pessoas já conhecem boa parte dos fazeres e quando prestigiam trabalhos muitas vezes lançam juízos de valor. Devemos pensar e passar a fazer arte apenas para aquelas pessoas que estão de fora desse meio, desse contexto, formando assim novos públicos. A Dança, o Teatro, a Performance, a arte de um modo geral, é transformadora, sobretudo se ela acontece nas bordas, atingindo um maior número de espectadoras.

Além de inserir a dança, a arte, nos espaços urbanos, é nosso dever integrar o público nos fazeres artísticos, numa constante relação, para que elas se sintam parte fundamental daquele cenário. Com isso, vejo o quão significativo é garantir a relação imbricada entre os conhecimentos acadêmicos aos da socie- 
dade, entendendo que esse é apenas um pequeno passo para uma arte em contínua retroalimentação.

Notei que é de suma importância que pesquisadoras pensam suas artes como composições urbanas e que sejam (re) conhecidas por isso, sobretudo quando partem da perspectiva enquanto integração do público presente, tal como Dudude Herrmann (MG), Bia Medeiros (UnB), Benjamin Taubkin (SP), uma vez que nossos corpos necessitam de novos moldes, de transformações que vêm das artes para o contexto social. Vi no cenário urbano inúmeras potências e interatividade entre o eu e a outra.

Ocupar e ressignificar os espaços, principalmente aqueles qualificados como inapropriados para acontecerem manifestações artísticas, como ocorre em algumas ruas e avenidas pelo Brasil, a meu ver, é primordial por ser a arte, de um modo geral, algo que toca aquela que faz e quem assiste, possibilitando assim aberturas de novos entendimentos. A partir de ações como essa, organizada pelo Festival de Inverno da UFMG, é possível perceber a dança livre em sociedade. No entanto, vale salientar o quão essencial é a existência de políticas públicas para que possamos ter acesso à arte.

Minha ida à cidade de Belo Horizonte só se tornou possível graças a CAPES Brasil e ao PPGArC da UFRN, os quais financiaram o deslocamento, para então eu ter contato com renomadas artistas e pesquisadoras brasileiras, como a pedagoga em dança Dudude Herrmann, o músico Benjamin, dentre outras pessoas que fizeram parte do evento. Por fim, pude horizontalizar minha visão, proporcionar mudanças físicas e artísticas, bem como conhecer novas metodologias de pesquisar a intersecção entre dança, música e sociedade, as quais ficaram registradas em mim novas tessituras e modos de pensar/fazer práticas artísticas. 


\section{REFERÊNCIAS}

GENNEP, Arnold van. Os ritos de passagem. Rio de Janeiro, Petrópolis: Vozes, 2011.

LARROSA, Jorge. Tremores: escritos sobre experiência. Belo Horizonte: Autêntica Editora, 2017.

NUNES, João Vítor Ferreira. A força e a chuva feminina em um sertão bem masculino: imersão performática nos ritos de passagem de Bia Mulato pela mitodologia em arte, 2019. Dissertação (Mestrado em Artes Cênicas) - Centro de Ciências Humanas, Letras e Artes, Universidade Federal do Rio Grande do Norte, Natal. 